\title{
Cytogenetic Studies on Three Species of Genus Burmagomphus of Family Gomphidae (Odonata: Anisoptera) from India
}

\author{
Walia Gurinder Kaur*, Chahal Sarabjit Singh and Singh Navdeep \\ Department of Zoology and Environmental Sciences, Punjabi University, Patiala, Punjab, India \\ *Corresponding Author
}

Received: $27^{\text {th }}$ April, 2021

Accepted: $30^{\text {th }}$ May, 2021

Published online: $3^{\text {rd }}$ June, 2021

https://doi.org/10.33745/ijzi.2021.v07i01.022

\begin{abstract}
Male germ cell chromosomes of Burmagomphus divaricatus, Burmagomphus pyramidalis and Burmagomphus sivalikensis of family Gomphidae have been investigated by using conventional staining, C-banding, silver nitrate staining and sequence specific staining. The species were collected from Punjab and Himachal Pradesh, India. All the species possess the chromosome number $2 n=23$ which is the type number of the family. Terminal C bands and NOR's are present at the autosomal bivalents and X chromosome is C positive and NOR rich in all the three species, while $\mathrm{m}$ bivalents show variation in distribution of $\mathrm{C}$ - heterochromatin and NOR's. In the sequence specific staining, whole complement shows bright DAPI signals in $B$. divaricatus, bright $\mathrm{CMA}_{3}$ signals in $B$. pyramidalis and both DAPI and $\mathrm{CMA}_{3}$ signals in B. sivalikensis.
\end{abstract}

Keywords: Gomphidae, Burmagomphus, Conventional staining, C- banding, Silver nitrate staining, Sequence specific staining

Citation: Walia Gurinder Kaur, Chahal Sarabjit Singh and Singh Navdeep: Cytogenetic studies on three species of genus Burmagomphus of family Gomphidae (Odonata: Anisoptera) from India. Intern. J. Zool. Invest. 7 (1): 272-277, 2021. https://doi.org/10.33745/ijzi.2021.v07i01.022

\section{Introduction}

Taxonomically, 1004 species of family Gomphidae are known worldwide, while 83 species are present in India. Cytogenetic data is available only for 71 species which also includes 21 species from India (Asana and Makino, 1935; Oksala, 1945; Das, 1956; Dasgupta, 1957; Cumming, 1964; Cruden,
1968; Kiauta, 1969, 1972, 1975, 1979; Tyagi, 1977, 1978 a,b, 1982, 1985, 1986; Ferreira et al., 1979; Zhu and Wu, 1986; Suzuki and Saitoh, 1988; Walia and Sandhu, 1999; Perepelov and Bugrov, 2001; Perepelov et al., 1998, 2001, Walia et al., 2006, Chahal, 2013; Walia and Chahal, 2014, 2020). Majority of the 
species possess $2 \mathrm{n}=23$, which is the type number of the family, while variation due to presence/absence of $\mathrm{m}$ chromosomes, presence of neo-XY sex determination resulted by the fusion of an autosome with sex element have been observed in few species. Genus Burmogomphus contains 30 species, while only 3 species are studied cytogenetically (Tyagi, 1977, 1978b, 1982; Chahal, 2013). In this study, structure and behaviour of the chromosomes during meiosis, detection of constitutive heterochromatin, location of NORs' and presence of AT and GC rich region across the chromosomes of B. divaricatus, B. pyramidalis and B. sivalikensis of genus Burmagomphus have been studied and compared. Among these, chromosome complements of $B$. divaricatus and $B$. sivalikensis have been described for the first time.

\section{Materials and Methods}

The live and adult specimens were collected from the areas of Punjab and Himachal Pradesh, India. Adult specimens were dissected in saline solution (0.69\%), testes were extirpated, kept for 45 minutes in sodium citrate $(0.9 \%)$ then fixed in Carnoy's fixative and tapped on grease free slides. Prepared slides were treated for different cytogenetic staining techniques like conventional staining (Carr and Walker, 1961), C- banding (Sumner ,1972), Silver nitrate staining (Howell and Black, 1980) and Sequence specific staining (Rebagliati et al., 2003).

\section{Results}

In all the three species, diakinesis possesses 12 elements, among these, 11 are autosomal bivalents, including small sized $\mathrm{m}$ bivalent and one large univalent, showing bipartite behaviour is $\mathrm{X}$ chromosome. The $\mathrm{m}$ bivalent is achiasmatic in $B$. divaricatus and $B$. sivalikensis, while showing terminal chiasma is $B$. pyramidalis (Figs. 1a, 2a, 3a). At metaphase I, all the autosomal bivalents are rod shaped with central constriction due to condensation and $\mathrm{X}$ chromosome shows bipartite behaviour (Figs. 1b, 2b, 3b).

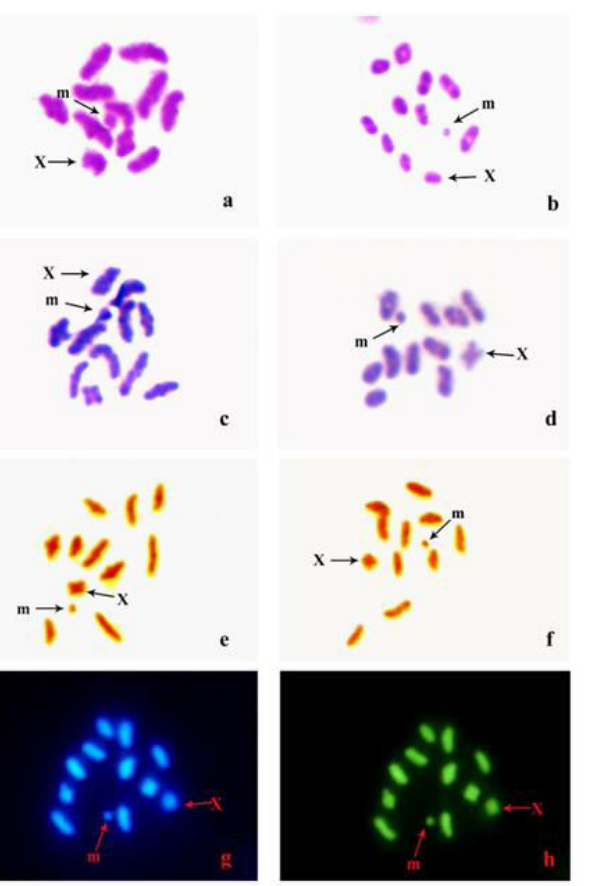

Fig. 1: Burmagomphus divaricatus- Conventional staining (a: diakinesis, b: metaphase-I), C- banding (c: diakinesis, d: metaphase-I), Silver nitrate staining (e: diakinesis, f: metaphase-I), Sequence specific staining (g, h) (DAPI: metaphase-I, CMA 3 : metaphase-I).

During the diakinesis and metaphase I, all autosomal bivalents show terminal C-bands and bipartite $\mathrm{X}$ chromosome is C-positive, while $\mathrm{m}$ bivalent is $\mathrm{C}$-positive in $B$. divaricatus and $B$. pyramidalis and C-negative in $B$. sivalikensis (Figs. 1c, 1d, 2c, 2d, 3c, 3d). At diakinesis and metaphase $\mathrm{I}$, all the autosomal bivalents show terminal NOR's, while $\mathrm{m}$ bivalent possesses dim NOR's due to small size, whereas $\mathrm{X}$ chromosome possesses 


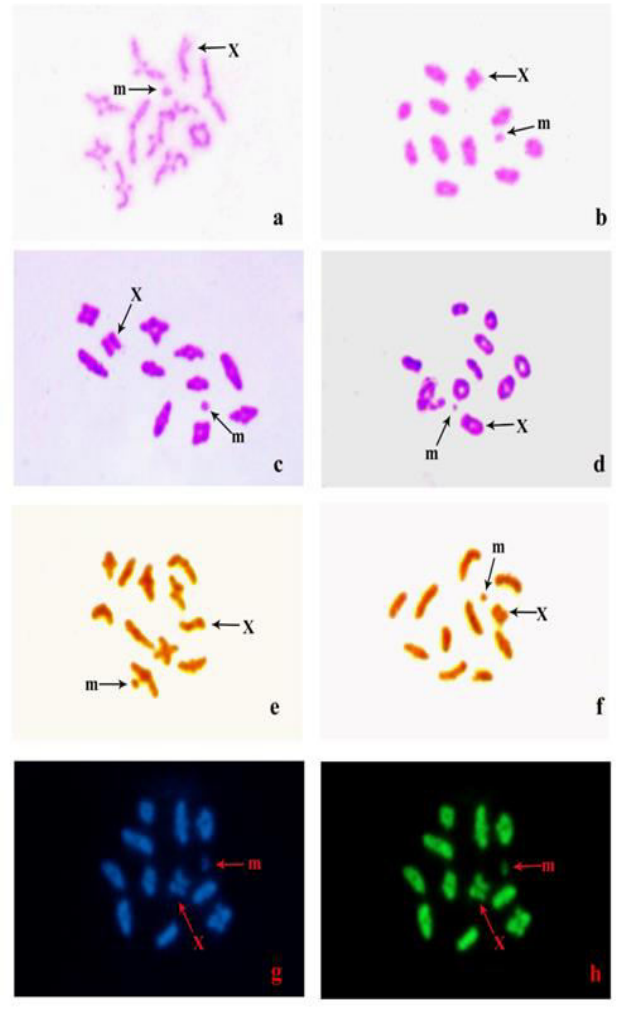

Fig. 2: Burmagomphus pyramidalis - Conventional staining (a: diakinesis, b: metaphase-I), C- banding (c: diakinesis, d: metaphase-I), Silver nitrate staining (e: diakinesis, f: metaphase-I), Sequence specific staining (g, h) (DAPI: metaphase-I, CMA 3 : metaphase-I).

bipartite behaviour and NOR's rich in all the species (Figs.1e, 1f, 2e, 2f, 3e, 3f).

At metaphase I, all the autosomal bivalents and $\mathrm{X}$ chromosome are DAPI bright than $\mathrm{CMA}_{3}$ while $\mathrm{m}$ bivalent possesses light DAPI and $\mathrm{CMA}_{3}$ signals due to its small size in $B$. divaricatus (Figs. 1g, 1h). In B. pyramidalis, all the autosomal bivalents including $\mathrm{m}$ bivalent and bipartite $\mathrm{X}$ chromosome show more $\mathrm{CMA}_{3}$ bright signals (Figs. 2g, 2h) and in $B$. sivalikensis, all the autosomal bivalents including $\mathrm{m}$ bivalent and $\mathrm{X}$ chromosome

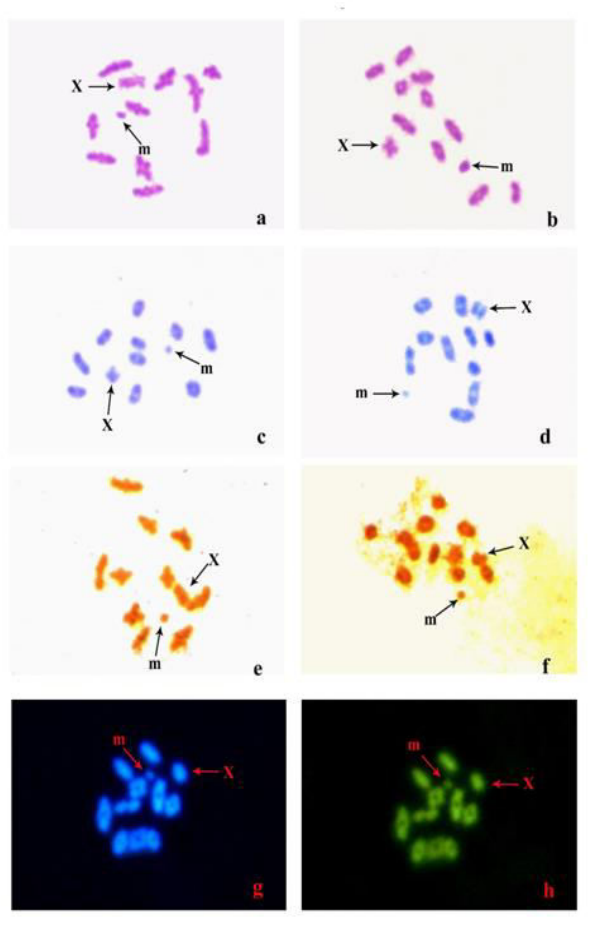

Fig. 3: Burmagomphus sivalikinesis- Conventional staining (a: diakinesis, b: metaphase-I), C- banding (c: diakinesis, $d$ : metaphase-I), Silver nitrate staining (e: diakinesis, f: metaphase-I), Sequence specific staining ( $g$, h) (DAPI: metaphase-I, $\mathrm{CMA}_{3}$ : metaphase-I).

reveals both DAPI and $\mathrm{CMA}_{3}$ signals (Figs. 3g, $3 h)$.

\section{Discussion}

The modal number of the family Gomphidae is $2 n=23$ as it is present in majority of the species. The reduced chromosome number in the family is originated from the primary complement $2 \mathrm{n}=25$ of the suborder Anisoptera by fusion of autosomes or fusion between an autosome with sex element (Kiauta, 1969). XO/XX type of sex mechanism is present in 67 cytogenetically studies species, while 4 species show with neo-XY sex determining mechanism. 
Table 1: Earlier reports on Burmagomphus

\begin{tabular}{|c|c|c|c|c|}
\hline S.No. & Name of the species & Locality & Chromosome number & Reference \\
\hline 1. & Burmagomphus arboreus Lieftinck, 1940 & India & $\mathrm{n}=12 \mathrm{~m}$ & Tyagi, 1978b, 1982 \\
\hline 2. & Burmagomphus pyramidalis Laidlaw, 1922 & India & $\mathrm{n}=12 \mathrm{~m}$ & Tyagi, 1977, 1982 \\
& & & & Present Study \\
\hline 3. & Burmagomphus williamsoni Forster, 1914 & India & $\mathrm{n}=12 \mathrm{~m}$ & Chahal, 2013 \\
\hline 4. & Burmagomphus divaricatus Lieftinck, 1964 & India & $\mathrm{n}=12 \mathrm{~m}$ & Present Study \\
& & & & \\
\hline 5. & Burmagomphus sivalikensis Laidlaw, 1922 & India & $\mathrm{n}=12 \mathrm{~m}$ & Present Study \\
\hline
\end{tabular}

In India, only 13 species, out of 71 cytogenetically studied species of family Gomphidae have been described (Asana and Makino, 1935; Das, 1956; Dasgupta, 1957; Tyagi, 1977, 1978a, b, 1982, 1986; Walia and Sandhu, 1999; Walia et al., 2006; Chahal, 2013; Walia and Chahal, 2014, 2020).

Genus Burmagomphus contain 30 species, while only 3 species have been described cytogenetically from India (Tyagi, 1977, 1978b, 1982; Chahal, 2013). All the species possess $2 \mathrm{n}=23 \mathrm{~m}$ with XO-XX sex mechanism. In the present study, $B$. divaricatus, $B$. pyramidalis and $B$. sivalikensis also possess $2 \mathrm{n}=23$ with $\mathrm{XO}-\mathrm{XX}$ sex mechanism which is in accordance to the earlier reports (Table 1). All the species of genus Burmagomphus show the presence of large $\mathrm{X}$ chromosome, which might be originated by the fusions. This process is divided into three stages, with an intermediate neo- $X$ neo neo- $Y$ type of sex determination and a final stage with reduction in two elements in diploid stage (Kiauta, 1969). Among these, B. divaricatus and B. sivalikensis have been studied for the first time.

C- banding and silver nitrate staining have been done on all the 3 species of the genus. Cbands and NOR's are present mostly at the terminal ends of autosomal bivalents and $\mathrm{X}$ chromosome is C- positive and NOR rich, while $\mathrm{m}$ bivalent show variations. Sequence specific staining shows the presence of overlapping AT and GC rich regions which are in accordance to the results of C-banding and silver nitrate staining.

\section{Conclusion}

Cytogenetic analysis on $B$. divaricatus, $B$. pyramidalis and $B$. sivalikensis of genus Burmagomphus of family Gomphidae have been done by using conventional staining, Cbanding, silver nitrate staining and sequence specific staining. All the species possess the chromosome number $2 \mathrm{n}=23$ with Xo-XX sex determination. Terminal C-bands and NOR's are present on all the autosomal bivalents, while $\mathrm{m}$ bivalent shows variation in 
C-heterochromatin and NOR's. Sequence specific staining shows the presence of overlapping AT and GC rich regions which are in accordance to the results of $\mathrm{C}$-banding and silver nitrate staining.

\section{Acknowledgement}

Authors are thankful to the Head, Department of Zoology and Environment Science, Punjabi University, Patiala for providing the lab facilities and Council of Scientific and Industrial Research, New Delhi (India) for the financial support under the scheme CSIR-UCG NET (JRF).

\section{References}

Asana JJ and Makino S. (1935) A comparative study of the chromosomes in the Indian dragonflies. J Faci Sci. 4: 67-86.

Carr DH and Walker JE. (1961) Carbol-fuchsin as a stain for human chromosomes. Stain Technol. 30: 233-236.

Chahal SS. (2013) Cytogenetical studies on some species of family Gomphidae. M. Phil. Dissertation, Punjabi University, Patiala, India.

Cruden RW. (1968) Chromosome numbers of some North American dragonflies (Odonata). Can J Gen Cytol. 10: 200-214.

Cumming RB. (1964) Cytogenetic studies in the order Odonata. Ph. D. Thesis, University of Texas, Austin.

Das C. (1956) Studies on the association between nonhomologous chromosomes during meiosis in four species of the Indian dragonflies (Odonata). J Zool Soc India 8: 129- 132.

Dasgupta J. (1957) Cytological studies of some Indian dragonflies. II: A study of the chromosomes during meiosis in thirty species of Indian Odonata (Insecta). Proc Zool Soc Calcutta 10: 1- 65.

Ferreira A, Kiauta B and Zaha A. (1979) Male germ cell chromosomes of thirty-two Brazilian dragonflies. Odonatologica 8: 5-22.

Howell M and Black DA. (1980) Controlled silver staining of nucleolar organizer regions with protective colloidal developer: I step method. Experientia 36: 104-105.

Oksala T. (1945) Zytologische Studien an Odonaten III. Die Ovogense. Ann Acad Scientiarum Fenn. 9: 1-32.
Kiauta B. (1969) Sex chromosomes and sex determining mechanism in Odonata, with a review of the cytological conditions in the family Gomphidae and references to the karyotypic evolution in the order. Genetica 40: 127-157.

Kiauta B. (1972) Synopsis on the main cytotaxonomic data in the order Odonata. Odonatologica 1: 73-102.

Kiauta B. (1975) Cytotaxonomy of dragonflies, with special reference to the Nepalese fauna. Nepal Res Cen. 1-78.

Kiauta B. (1979) The karyotype of some Anisoptera from Surinam. Odonatologica 8: 267-283.

Perepelov E and Bugrov AG. (2001) C-heterochromatin in chromosomes of Ophiogomphus cecilia cecilia (Four.) (Anisoptera: Gomphidae) with notes on the sex chromosome origin in the species. Caryologia 54: 169-172.

Perepelov EA, Bugrov AG and Warchalowska-Sliwa E. (1998) C-banded karyotypes of some dragonfly species from Russia. Folia Biol. 46: 137-142.

Perepelov EA, Bugrov AG and Warchalowska-Sliwa, E. (2001) C-banded karyotypes of some dragonfly species from Russia. II. The families Cordulegasteridae, Corduliidae and Gomphidae. Folia Biol. 49: 175-178.

Rebagliati PJ, Papeschi AG and Mola LM. (2003) Meiosis and fluorescent banding in Edessa meditabunda and E. rufomarginata (Heteroptera: Pentatomidae: Edesinae). Eur J Entomol. 100: 11-18.

Sumner AT. (1972) A simple technique for demonstrating centromeric heterochromatin. Exp Cell Res 75: 304-306.

Suzuki K and Saitoh K. (1988) Germ-line chromosomes of two species of Davidius, with special reference to the sex chromosomes (Anisoptera: Gomphidae). Odonatologica 17: 275-280.

Tyagi BK. (1977) A note on the karyotypes of Burmagomphus pyramidalis Laidlaw and Onychogomphus saundersi duaricus Fraser (Anisoptera: Gomphidae). Odonatologica 6: 277-282.

Tyagi BK. (1978a) Studies on the chromosomes of Odonata of Dun Valley (Dehradun, India). Ph. D. Thesis, University of Garhwal, Srinagar, India

Tyagi BK. (1978b) The chromosome number and sex determining mechanisms, newly recorded in thirteen Indian dragonflies (Odonata). Chromo Info Serv. 25: 5-7.

Tyagi BK. (1982) Cytotaxonomy of the Indian dragonflies. Indian Rev Life Sci. 2: 149-161. 
Tyagi BK. (1985) Cytotaxonomy of the genus Onychogomphus Selys (Odonata: Anisoptera, Gomphidae), with special reference to the evolution of the sex- determining mechanism and the reduced chromosome number in the family Gomphidae. Proceedings of $1^{\text {st }}$ Indian Symp Odonatology, Madhurai. pp. 217-228.

Tyagi BK. (1986) Cytogenetics, Karyosystematics and Cytophylogeny of the Indian Odonata. Indian Rev Life Sci. 6: 215-229.

Walia GK and Sandhu R. (1999) Karyological investigation on Davidius zallorensis zallorensis (Gomphidae: Anisoptera: Odonata). Chromo Sci. 3: 43-44.

Walia GK and Chahal SS. (2014) Distribution of constitutive heterochromatin and nucleolar organizer regions in two species of family Gomphidae (Odonata: Anisoptera). The Nucleus 57: 223-227.
Walia, GK and Chahal, SS. (2020) Linear differentiation of chromosomes of Anisogomphus bivittatus selys, 1854 from India (Odonata: Anisoptera: Gomphidae). Intern J Ento Res. 2: 120-122.

Walia GK, Sandhu R and Goyal S. (2006) Cytogenetical analysis of Nepogomphus modestus from Palampur area of Himachal Pradesh, India (Gomphidae: Anisoptera). Chromo Sci. 9: 99-100.

Zhu HQ and Wu JI. (1986) Notes on the male germ cell karyotypes of some Odonata from the Shanxi Province, China. Notulae Odonatol. 2: 118-120. 